Revista de Ensino em Artes, Moda e Design

Dossiê 5

As fontes de pesquisa para moda. Uma aproximação interdisciplinar e arquivista da história da moda: pesquisa e ensino.

\title{
ENTRE MÉTODOS E PRÁTICAS: AS FONTES HISTÓRICAS APLICADAS À MODA COMO OBJETO DE PESQUISA*
}

\author{
Between methods and practices: the historical \\ sources applied to fashion as a research object
}

\section{Entre méthodes et pratiques: les sources historiques appliquées à la mode comme objet de recherche}

\section{Everton Vieira Barbosa ${ }^{1}$}

1 Doutorando pelo Programa de Pós-Graduação em História pela Universidade Federal Fluminense (UFF). Bolsista CAPES. E-mail: semusico@hotmail.com | Lattes: http://lattes.cnpq.br/3719090115264390 | Orcid: http://orcid.org/0000-0003-2480-7397 


\section{Resumo}

Ao utilizar a moda como objeto de pesquisa, este artigo trata dos diversos tipos de documentos utilizados pela historiografia desde o último quartel do século XX, pensando, analisando e problematizando seus usos e métodos práticos no contexto acadêmico e escolar para a construção do conhecimento. Partindo do pressuposto de que as questões levantadas aos distintos documentos (impressos, digitais, institucionais, inventariais, epistolários, literários, imagéticos, orais, cinematográficos, musicais e materiais) contribuem para a construção de fontes históricas, faremos uma breve reflexão acerca de algumas pesquisas realizadas a fim de ilustrar a gama de perspectivas analíticas que possam contribuir para o diálogo entre a História e a Moda. Esta proposta metodológica permitiu refletir e compreender os cuidados que devem ser tomados na utilização de diferentes documentos históricos, bem como a importância das problemáticas levantadas, possibilitando o cruzamento de fontes e a sapiência na construção de narrativas que deem visibilidade à moda utilizada por indivíduos e grupos, em distintas sociedades, no tempo e no espaço histórico.

Palavras-Chave: Moda. Fontes históricas. Metodologia

\section{Summary}

By using fashion as a research object, this article deals of the various types of documents used by historiography since the last quarter of the twentieth century, thinking, analyzing and problematizing its uses and practical methods in the academic and school context for the construction of knowledge. Starting from the assumption that the issues raised in the different documents (printed, digital, institutional, inventory, epistolary, literary, imagery, oral, cinematographic, musical and material) contribute to the construction of historical sources, we will briefly reflect on some research conducted to illustrate the range of analytical perspectives that can contribute to the dialogue between history and fashion. This methodological proposal allowed to reflect and understand the care that must be taken in the use of different historical documents, as well as the importance of the problems raised, enabling the crossing of sources and the wisdom in the construction of narratives that give visibility to the fashion used by individuals and groups, in different societies, in time and in historical space .

Keywords: Fashion. Historical sources. Methodology.

\section{Résumé}

En utilisant la mode comme objet de recherche, cet article porte sur différents types de documents utilisés par l'historiographie depuis le dernier quart du XXe siècle, en réfléchissant, analysant et problématisant ses utilisations et ses méthodes pratiques dans le contexte académique et scolaire, pour la construction du savoir. En supposant que les questions soulevés dans les différents sources (imprimés, numériques, institutionnels, inventaires, épistolaires, littéraires, imagétiques, orales, cinématographiques, musicaux et matériels) contribuent à leur construction de sources historiques, nous ferons une brève réflexion sur quelques recherches déjà réalisées afin d'illustrer la gamme de perspectives analytiques qui peut contribuer au dialogue entre l'histoire et la mode. Cette proposition méthodologique a permis de réfléchir et de comprendre les précautions qui doivent être pris pour bien utiliser différents documents historiques, ainsi que l'importance des problématiques soulevées, permettant le croisement des sources et la sagesse dans la construction de récits qui offrent une visibilité à la mode utilisée par les individus et les groupes, dans différentes sociétés dans le temps et l'espace historique.

Mots-clés: Mode. Sources historiques. La méthodologie. 


\section{INTRODUÇÃO}

$\mathrm{Na}$ medida em que se ampliaram as pesquisas no Brasil sobre história e moda, percebemos a importância e a necessidade de levantar algumas questões e dar atenção aos cuidados metodológicos acerca deste tema. Para isso, vamos refletir sobre as ferramentas disponíveis para estudar a moda como objeto de conhecimento e, com isso, manter o rigor científico que é requisitado nos trabalhos acadêmicos.

Sob a perspectiva histórica, propomos apresentar, problematizar e analisar os distintos tipos de documentos - impressos, digitais, institucionais, inventariais, epistolários, literários, imagéticos, orais, cinematográficos, musicais e materiais - que podem servir como fonte para a produção de saberes, apreendendo a moda como objeto de pesquisa. A apresentação destes documentos, bem como sua problematização e análise, faz parte do procedimento metodológico adotado neste trabalho, justificado pela ampliação das perspectivas de pesquisa nos campos da história e da moda.

Desta maneira, faremos inicialmente uma breve explanação do campo historiográfico no início deste século, seguido pela apresentação de algumas perspectivas de análise dos distintos documentos utilizados como fontes históricas. De maneira sincronizada, apontaremos os cuidados e as possibilidades metodológicas de utilização destes materiais tomando a moda como ferramenta de análise.

Precisamos salientar que esta proposta não tem a pretensão de se tornar um manual metodológico com a necessidade de ser seguido piamente e nem de servir como um tutorial, instruindo o "passo-a-passo" de uma pesquisa, até porque, este assunto não se esgota nas questões e nas problemáticas aqui levantadas. Portanto, queremos sinalizar e sugerir, com este texto, algumas possibilidades de análise que podem ser utilizadas nos diversos tipos de pesquisas e, assim, contribuir para a ampliação dos estudos e diálogos entre a História e a Moda.

\section{O CAMPO HISTORIOGRÁFICO NO SÉCULO XXI: ENTRE DOCUMENTOS E FONTES}

Desde fins do século $X X$, em especial pela crise de paradigmas iniciada na década de 1970, o campo historiográfico vem ganhando novos objetos e novas perspectivas de análise. A principal mudança se deu na possibilidade plural de documentos utilizados pela historiografia para a produção do conhecimento, bem como nas problemáticas, abordagens e objetos que se colocavam sobre estes materiais. Sem deixar de considerar "as estruturas, a longa duração, e os grupos sociais", Helenice Rodrigues da Silva aponta que a guinada crítica da corrente historiográfica francesa passou a levar em conta "as escalas de análise, os atores individuais e a escrita da História" (SILVA, 2007 p. 169), ilustrada pelo uso da narrativa, da argumentação e da subjetividade na produção historiográfica.

Tal posicionamento deve-se à produção, circulação e recepção das novas correntes historiográficas, que alteraram o posicionamento do historiador frente aos critérios de análise e abordagens das fontes de pesquisa utilizadas, na construção da narrativa histórica. Enquanto o estudo das estruturas de longa duração (BRAUDEL, 1965) foi analisado pela escala da microhistória italiana, os trabalhos sobre os grupos e atores sociais obtiveram visibilidade por meio da abordagem da história social inglesa e pela história do 
cotidiano alemão. Deste modo, a escrita da História recebeu novas interpretações sob a perspectiva da virada linguística norte-americana.

Analisando o retorno do sujeito na narrativa histórica, Bernard Lepetit destaca que as modalidades de escalas cronológicas, sem deixar de considerar a longa duração, "revalorizam o curto prazo, o do acontecimento entendido como ação situada" e "o da experiência humana direta ou indireta" (LEPETIT, 2001, pp. 241-242). A ação situada, de que trata o pesquisador, pode ser interpretada como as práticas sociais, as quais Roger Chartier apreende como "complexas, múltiplas, diferenciadas, que constroem o mundo como representação" (CHARTIER, 2002, p. 28).

Preocupados com os sujeitos como agentes de seu devir histórico, as especificidades de análises utilizadas por cada corrente historiográfica foram incorporadas por vários historiadores ao redor do mundo, permitindo a pluralidade de fontes. Na medida em que foram levantadas, novas interrogações e exclamações surgiram sobre a ação humana na escrita da história. O livro Sujeitos na História: perspectivas e abordagens, organizado por Giselle Martins Venancio, Larissa Vianna e Maria Verónica Secreto, aponta uma importante mudança na postura do historiador ao querer identificar as ações humanas e suas conexões com os acontecimentos. Nota-se que estes sujeitos estão "inseridos em processos cujos constrangimentos sociais promovem maior ou menor possibilidade de alargamento da liberdade de atuação" (2017, p. 16).

Neste processo de valorização do sujeito, abarcando novos métodos e abordagens de análise, outros objetos de pesquisa receberam a atenção do historiador para a interpretação da sociedade. Dentre estes objetos, podemos mobilizar a moda, considerada nesta pesquisa "como um sistema de significantes, uma atividade classificadora, uma ordem bem mais semiológica que semântica" (BARTHES, 1979, p. 264).

Mas antes de tratarmos a moda como objeto de pesquisa na perspectiva histórica, deve-se considerar que as diversas fontes utilizadas por este campo, e que serão tratadas a seguir, não podem ser assimiladas naturalmente pelo pesquisador. Em outras palavras, antes de se tornarem fontes, elas passam por um processo de reflexão, problematização, levantamento e análise de fundamentos teóricos e metodológicos para a elaboração de uma narrativa. Este processo sistemático e complexo é descrito pela pesquisadora Silvia Hunold Lara como um ato "invenção", ou seja, o ato de criar meios para estudar e interpretar as fontes a partir das interrogações, dos métodos e das abordagens que são colocadas pelo historiador e por demais pesquisadores nos documentos que tem à sua disposição para análise (LARA, 2008, p. 18). Também é preciso esclarecer que, neste processo, nem todo documento pode ser considerado fonte. Será a partir das questões, das reflexões, das análises, do levantamento teórico e metodológico feito pelo pesquisador e pelo fornecimento de "informações sobre as ações humanas do passado" que o documento tornar-se-á fonte de pesquisa (LARA, 2008, p. 18).

A partir destes esclarecimentos, apresentamos os diferentes tipos de documentos - impressos, digitais, institucionais, inventariais, epistolários, literários, imagéticos, orais, cinematográficos, musicais e materiais - que podem servir como fonte para a construção de saberes. Na medida em que forem apresentados, pontuaremos os cuidados necessários para a produção do conhecimento científico, ao mesmo tempo em que analisaremos distintos trabalhos que utilizaram algumas destas fontes para abordarmos a moda como objeto de estudo. 


\section{FONTES PARA ESTUDOS DA MODA: ENTRE MÉTODOS E PRÁTICAS}

Dentre as fontes mais acessíveis nas pesquisas históricas do século XXI, a imprensa pode ser encarada como protagonista tanto por sua rápida difusão, especialmente na era digital, quanto por tratar de diversos assuntos para os mais variados públicos. Assim, os impressos possuem um leque de possibilidades analíticas, que devem ser questionados criteriosamente, para não tornar o documento um receptáculo de constatações e comprovações já pensadas de modo teleológico. É necessário analisar os documentos a partir das questões levantadas, das análises adotadas, dos procedimentos teórico-metodológicos empregados, a fim de obter respostas para a produção de uma narrativa histórica.

Neste processo de estudo das fontes Tania Regina de Luca apresenta alguns critérios metodológicos que contribuem para pensarmos os questionamentos que podem ser feitos aos documentos impressos. Dentre outros aspectos, está a materialidade dos periódicos. Podemos considerar, por exemplo, sua composição física, seu formato, o tipo de papel, a qualidade da impressão, as cores usadas, e as imagens inseridas. Estes elementos podem sinalizar os acordos tipográficos realizados entre os proprietários do jornal e demais comerciantes, os recursos financeiros mobilizados na produção deste material, seus interesses políticos, econômicos e sociais e as técnicas existentes para a produção daquele tipo de material.

A atenção ao aspecto material dos jornais e das revistas nos leva a pensar em sua tiragem, sua difusão e sua circulação micro e macroespacial, ou seja, nas cidades, estados e demais países onde o impresso foi publicado ou, ainda, por onde circulou. Também é necessário indagar sobre quais os locais de subscrição, os indivíduos envolvidos, direta e indiretamente, na produção deste material, "as funções sociais desses impressos", e a que público o periódico era destinado (LUCA, 2008, p. 132).

Quando questionamos quem era o público-alvo dos impressos, adentramos em exclamações que perpassam sua textualidade. Pensar o título, o subtítulo, a disposição das colunas e das matérias, o texto-imagem, a quantidade de páginas e os assuntos tratados, ajudam a identificar a qual público este material buscava atingir. Ao mesmo tempo, permite refletir e problematizar os textos escolhidos para serem publicados, e quais os interesses pessoais e coletivos no âmbito econômico, político e social. Deste modo, é preciso contextualizar a produção impressa, ou seja, historicizá-la. Para isso, é importante "ter em conta, portanto, as condições técnicas de produção vigente e a averiguação, dentre tudo que se dispunha, do que foi escolhido e por quê" (LUCA, 2008, p. 132).

Assim como Tania de Luca, as historiadoras Maria do Rosário da Cunha Peixoto e Heloísa de Faria Cruz também abordam alguns critérios metodológicos que podem ser adotados em pesquisas que utilizam documentos impressos para a produção do conhecimento (PEIXOTO; CRUZ, 2007). A atenção dada à identificação do periódico, ao projeto gráfico-editorial, aos indivíduos e grupos envolvidos, às condições técnicas e econômicas, ao posicionamento político, aos aspectos de produção e distribuição, à circulação e à recepção abrem uma gama de possibilidades analíticas na qual o pesquisador precisará considerar quando tratar de seu objeto de estudo, utilizando a imprensa enquanto fonte de pesquisa.

Ao utilizar a moda como objeto de análise, Ana Cláudia Suriani da Silva "examina o papel da imprensa na divulgação da moda e a natureza transnacional da revista de moda 
desde o seu surgimento" (SILVA, 2017, p. 179). A pesquisadora destacou a importância da imprensa no século XIX, enquanto recurso tecnológico eficaz na transmissão de informações sobre a moda para outros países. Caracterizada como um instrutor pedagógico, a imprensa da moda moldava certos hábitos sociais de vestir-se adequadamente em distintos espaços e, com isso, estabelecia determinados gostos entre suas leitoras. Como exemplo, podemos analisar o periódico O Jornal das Senhoras (1852-1855) para tratar a moda como objeto de pesquisa. No hebdomadário dominical, publicado por mulheres no Rio de Janeiro, e voltado ao público feminino praticamente $80 \%$ de suas edições contaram com ilustrações e descrições de moda parisiense, inseridas no impresso graças a um acordo estabelecido entre as redatoras no Brasil e o redator do periódico francês $L e$ Moniteur de la Mode (1843-1913).

O processo de tradução e transcrição dos artigos de moda francesa inseridos em O Jornal das Senhoras passava por um processo de mediação, realizada pelas redatoras, que também circulavam pelos estabelecimentos de modistas no Rio de Janeiro, especialmente na Rua do Ouvidor, em busca de informações sobre os tecidos, adereços e demais acessórios necessários para a reprodução da imagem desenhada na estampa de moda francesa (BARBOSA, 2018). Esse procedimento permite pensar as estratégias editoriais utilizadas pelas redatoras brasileiras na organização semanal do jornal e na busca pela manutenção e adesão de novos assinantes, ou ainda, indagarmos quem eram os comerciantes envolvidos neste processo. Deste modo, é possível também, observar como se dava a circulação transnacional de periódicos, tecidos e adereços ligados à criação de vestimentas no Brasil em meados do século XIX.

No caso da circulação transnacional de periódicos de moda, Ana Cláudia Suriani da Silva afirma ter sido uma realidade no século XIX, dado o crescimento do consumo urbano, estabelecido por um novo grupo de pessoas que crescia e se afirmava em suas identidades pessoais e sociais (SILVA, 2017, p. 193). Atenta também aos cuidados e às problemáticas que o uso da fonte impressa apresenta, a pesquisadora demonstra como seus aspectos físicos e econômicos, bem como de sua carga simbólica embutida nos textos e nas imagens que circulam de modo transnacional, contribuíram para materializar o gosto e o consumo da moda europeia no Brasil Oitocentista (SILVA, 2007).

A relação que Ana Cláudia Suriani da Silva estabelece entre moda e literatura para pensar as estratégias tipográficas que mobilizavam o gosto e o consumo das leitoras, por meio da moda europeia e dos textos literários, nos abre caminho para pensar este documento como fonte de pesquisa. Tendo ciência de que a produção literária não possui a mesma preocupação e as obrigações que a produção histórica possui, a respeito das "diferentes formas de apreensão de dimensões igualmente diferentes da realidade", Maria do Rosário da Cunha Peixoto levanta alguns cuidados para o uso da literatura enquanto fonte para a produção do conhecimento (PEIXOTO, 2011, p. 15).

Além de indagar a contextualização e a historicidade da produção literária e do ambiente na qual os personagens são descritos, é importante questionar quem eram o(s) indivíduo(s) ou o(s) grupo produtor(es) da narrativa, os personagens e quais seus papéis simbólicos, qual o público-alvo, quais os modos de produção, circulação, difusão e recepção da obra literária, e em quais suportes a literatura foi inserida (PEIXOTO, 2011, p. 30). 
Tais questionamentos estão vinculados às interrogações que perpassam a criação da narrativa literária. A atenção dada "para a especificidade da linguagem literária", a "reposição do texto literário nas condições históricas de sua produção", a análise da "relação fonte/linguagem" que insere o texto no campo ficcional são os principais cuidados e procedimentos metodológicos apontados por Maria do Rosário da Cunha Peixoto para o pesquisador que pretende utilizar a literatura enquanto fonte de pesquisa (PEIXOTO, 2011, p. 32). Estas problemáticas foram tratadas por Geanneti Tavares Salomon ao utilizar a obra Dom Casmurro (1899), escrita por Machado de Assis (1839-1908), para analisar a moda e sua relação com os personagens. Para estudar a moda enquanto conceito, a pesquisadora trata este objeto.

como um fenômeno semiológico, histórico e sociológico, capaz de apontar características culturais e sociais de um determinado povo, e mais profundamente, também capaz de demarcar o tempo, expor aspectos da personalidade das pessoas e da época em que viveram, explicitando ainda alterações em suas personalidades ao longo de suas existências, e servindo assim, à construção literária (SALOMON, 2010, p. 18).

Nesta perspectiva, Geanneti Tavares Salomon analisa a obra Dom Casmurro como "fonte de informações importante para complementar historicamente o estudo da moda de uma época", extraindo "além da moda, os costumes, o modo de viver da sociedade, o movimento sutil que ficou perdido em outras fontes" (SALOMON, 2010, p. 45).

Ciente de que a literatura por si só não é capaz de proporcionar à escrita histórica a apreensão da dimensão de verdade, que é própria de seu campo do conhecimento, a pesquisadora realiza o cruzamento de fontes literárias e imagéticas. Ela também analisa estudos acadêmicos sobre o período e o local em que a obra Dom casmurro foi produzida, para concluir que a produção literária de Machado de Assis "reflete um momento histórico específico, com as mudanças sociais, políticas, culturais do século XIX, e suas circunstâncias expostas na narrativa por meio de desdobramentos surpreendentes, como a moda" (SALOMON, 2010, p. 186).

As fontes imagéticas utilizadas pela pesquisadora nos direcionam a pensar e analisar os cuidados e os procedimentos metodológicos que devem ser adotados neste documento. Considerar um documento imagético como fonte requer "que o pesquisador se familiarize com as inúmeras variáveis que definem a natureza da imagem e a multiplicidade de significados e papéis que ela pode assumir historicamente" (MENESES, 2012, p. 244).

Nesta lógica, Ulpiano Toledo Bezerra de Meneses considera importante dar atenção à problemática do sentido que perpassa o campo imagético, a fim de superar determinadas perspectivas que fazem uso destas fontes apenas como ilustração ou confirmação de análises, recaindo ao esquema teleológico.

Desta forma, faz-se necessário pensar os efeitos da imagem na produção de códigos, o uso da perspectiva, a disposição dos componentes retratados na tela, o uso das cores, o tipo de tinta ou produto utilizado para criação da imagem. Além disso, deve-se questionar quem pintou a imagem, contextualizar a obra e cruzar outras fontes, inclusive imagéticas, a fim de verificar as correntes artísticas existentes no período e que precederam a obra e o pintor.

Quando analisamos as ilustrações de moda francesa impressas no periódico Le Moniteur de la Mode e reproduzidas em O Jornal das Senhoras podemos identificar 
certos elementos comuns, característicos do momento em que as imagens foram produzidas.

As leis suntuárias correspondem, portanto à sensatez dos governantes, mas Em meados da década de 1830 a maioria das placas representava duas mulheres, na esfera doméstica ou ao ar livre, envolvidas em atividades femininas de classe alta ou média, tais como particular de bailes - incluindo o baile de fantasias para crianças - recebendo uma visita no salão, tocando pianoforte, lendo livros ou revistas, escrevendo ou lendo cartas, fazendo bordado, esboçando, pintando, e passeando nos jardins, parques ou pelas propriedades rurais (HAHN, 2009, pp. 67-68).

Pintadas por Jean-Baptiste David (1808-1892), sob a encomenda do redator francês Adolphe Camille Goubaud, as ilustrações eram feitas com o uso de cores vivas a fim de destacar os vestidos, uma vez que as imagens eram inseridas em um periódico de moda, cujo objetivo era instruir as leitoras sobre os distintos espaços de sociabilidade em que cada traje poderia ser utilizado. Dessa maneira, promoveu-se um gosto cultural, um hábito social do consumo e um costume de vestir-se adequadamente para determinadas finalidades.

Assim como as ilustrações pintadas em distintos suportes físicos, as fotografias, com suas devidas especificidades técnicas, possuem certas aproximações nas quais podemos levantar questões ao tratá-las como fonte do conhecimento.

No caso das especificidades técnicas, faz-se necessário pensar no suporte que produziu a fotografia, nos recursos técnicos de luz, sombra, efeitos de brilho, foco, tratamentos, máscaras e toda gama de ferramentas disponíveis para a fixação da imagem construída em um tempo e espaço vivido.

Sob a perspectiva dos sentidos e dos significados atribuídos à fotografia enquanto documento revelador dos aspectos da vida, Ciro Flamarion Cardoso e Ana Maria Mauad concebem este material como um "agente do processo de criação de uma memória que deve promover tanto a legitimação de uma determinada escolha quanto, por outro lado, o esquecimento de todas as outras" (CARDOSO; MAUAD, 1997, p. 572).

Assim, as escolhas atribuídas na produção da imagem captada integram um sistema de signos não verbais, ou seja, assimilados pela metalinguagem, atrelada a uma existência autônoma acessada pela lembrança, e relativa à composição da mensagem fotográfica (CARDOSO; MAUAD, 1997, p. 573).

Atenta às fotografias como um recurso não verbal e não textual, mas que conferem sentidos e significados particulares ao espectador, Diana Crane examina as "respostas a representações de gênero nas fotografias de moda e anúncios de roupas entre mulheres jovens e de meia-idade, representantes de diversas etnias e nacionalidades" (CRANE, 2006, p. 414).

De maneira criteriosa, a seleção das fotografias "para representar diversos aspectos da hegemonia" (CRANE, 2006, p. 414) é pensada pela pesquisadora em seus meios técnicos e simbólicos. O meio técnico está voltado para as características de uma fotografia produzida para uma revista de moda, dando visibilidade aos efeitos de luz e sombra, brilho e intensidade no foco, assim como os demais recursos que são mobilizados para produzir uma imagem que seja aceita pelos diretores da revista.

\footnotetext{
1 Texto traduzido do original: "By the mid-1830s most plates depicted two women, in domestic ball or outdoor settings, engaged in upper or middle-class feminine activities, such as attending balls - including costume balls for children - receiving a visitor in the salon, playing the pianoforte, reading books or magazines, writing or reading letters, doing embroidery, sketching, painting, and promenading in gardens, parks or at country estates" (HAHN, 2009, pp. 67-68).
} 
Neste processo de aceitação recaem os aspectos simbólicos e que perpassam a escolha da modelo que será fotografada, a produção feita sobre seu corpo, no que tange a maquiagem, ao corte de cabelo e o posicionamento em frente à câmera. Também é pensado o traje que será utilizado, o cenário em que a imagem será forjada e os demais efeitos simbólicos que possam ser inseridos, a fim de agradar as consumidoras de modas.

Consciente de que as fotografias inseridas em revistas de modas visam ao lucro e a publicidade, devendo agradar aos anunciantes e ao público-alvo, Diana Crane considera que elas "expressam as tensões e contradições de uma hegemonia conflitante", tanto pelas "percepções tradicionais de comportamento pessoal", quanto pelas "concepções modernas de identidade social", que moldam "as percepções femininas da cultura pós-moderna" (CRANE, 2006, pp. 450-451).

O conflito existente na produção das imagens, relatado pelas mulheres entrevistadas, denota a atenção que deve ser dada à análise de fotografias e às imagens enquanto fonte de pesquisa, mas também no uso da oralidade para a produção do conhecimento. Ao extrair informações de um grupo de discussão composto por 45 mulheres de diferentes idades, origens raciais e nacionalidades, Diana Crane realizou várias perguntas, "formuladas com o objetivo de detectar as percepções acerca das fotografias e o grau em que as mulheres conseguiam se identificar com as modelos das fotos" (CRANE, 2006, p. 415).

A pesquisadora justificou o procedimento de utilizar grupos de discussão ao invés de entrevistas individuais porque as narradoras não estavam acostumadas a comentar fotos e poderiam ser influenciadas pelas respostas de outras mulheres, em determinadas questões. (CRANE, 2006, p. 414).

Diante das respostas obtidas pelas entrevistadas, Diana Crane compreende a pluralidade de percepções que as mulheres tinham a respeito das fotografias de revistas de modas. Neste sentido, a atenção dada à narrativa, enquanto fonte de pesquisa, deve ser problematizada para que o pesquisador não conduza e nem force determinadas respostas, mas que atue de maneira orgânica, coletando as respostas projetadas pelas entrevistadas de modo natural.

Na década de 1980, ao entrevistar um casal estadunidense afro-americano que vivenciou uma greve na década de 1930, o historiador italiano Alessandro Portelli realizou alguns procedimentos metodológicos que podem contribuir na utilização de oralidades enquanto fonte de pesquisa. O cuidado com a escolha dos entrevistados, o local da entrevista, a liberdade dada ao narrador na produção da oralidade, o suporte utilizado para arquivar a fala e, ainda, as perguntas criteriosamente preparadas e colocadas nos devidos momentos, são de grande importância para a construção de confiança entre o pesquisador e o narrador. Este último é considerado um ponto chave na apreensão de elementos esquecidos e/ou omitidos pelo entrevistado.

Para a interpretação da oralidade, Alessandro Portelli estabelece uma tipologia de modalidades narrativas, classificadas pelos pronomes utilizados no singular ou no plural para determinados tempos e espaços narrados (PORTELLI, 2010, p. 22). Certamente esta tipologia se altera de entrevista para entrevista, porém é um recurso linguístico importante para interpretar e analisar as narrativas organizadas e produzidas no presente sobre os atos que aconteceram no passado e são relembrados pelo entrevistado. 
Ao tratarmos de memória, é importante considerar que os conteúdos relatados são evocados e organizados verbalmente no diálogo interativo entre quem fala e quem escuta, não possuindo, portanto, uma obrigatoriedade com o tempo cronológico e o tempo da própria narrativa. Deste modo, respeitar a não linearidade da oralidade e o tempo narrativo do entrevistado é imprescindível para não distorcer os sentidos e os significados da fonte oral, construída a partir das questões levantadas, dos procedimentos teórico-metodológicos adotados e, posteriormente, da sua interpretação e análise.

Em algumas situações, o relato das experiências de vida podem contradizer as construções simbólicas coletivas, forjadas como tradições nacionais. O caso da entrevista de soldados australianos veteranos da Grande Guerra (1914-1918) é emblemático neste aspecto. Alistair Thomson desmitificou a lenda nacional dos Anzacs - nome que os soldados receberam - na medida em que as entrevistas coletadas contrastavam entre as experiências de vida dos veteranos e da percepção que o pesquisador possuía sobre a lenda (THOMSON, 1997, p. 55).

Entre lembranças, esquecimentos e silenciamentos, determinadas narrativas se apoiavam na lenda construída coletivamente. Com isso, compunham certas reminiscências que surgiam pelo tempo e pela fragilidade da memória. Neste ato de composição, o pesquisador Alistair Thomson compreende que

O processo de recordar é uma das principais formas de nos identificarmos quando narramos uma história. Ao narrar uma história, identificamos o que pensamos que éramos no passado, quem pensamos que somos no presente e o que gostaríamos de ser (THOMSON, 1997, p. 57).

Portanto, é importante que o pesquisador tenha a sensibilidade na interpretação do fato narrado enquanto uma produção da memória sobre a perspectiva do narrador. Afinal, assim como as fontes são criadas a partir das questões colocadas nos documentos, da análise e dos procedimentos teórico-metodológicos utilizados, a narrativa é parte dos resultados obtidos a partir das questões propostas pelo historiador e pelas abordagens escolhidas pelo narrador.

Da mesma forma que a oralidade é produzida a partir do acesso à memória e perpassa um critério de escolhas entre o que será falada e como será narrada, a fonte epistolar pode ser enquadrada no mesmo molde, tendo algumas especificidades. Enquanto a fonte oral é criada na oralidade e materializada na transcrição em parceria entre entrevistador e entrevistado, a fonte epistolar não é criada em conjunto com o pesquisador, com exceção de analfabetos que precisam ditar as cartas para alguém redigi-las.

Ao tratar das memórias de Aurélia Dias Rolemberg (1863-1952), o historiador Samuel Albuquerque dá visibilidade à atuação de preceptoras no Brasil Oitocentista, bem como denota elementos da moda vivenciada pela memorialista sergipana durante sua adolescência e estadia na cidade do Rio de Janeiro.

A atenção e os cuidados que recaem sobre as cartas, como fonte de pesquisa, estão na contextualização desse registro. Em outras palavras, deve-se questionar quem são remetente e destinatário, a localidade e ocasião da correspondência, em quais tipos de suporte material o documento foi produzido. Neste bojo interrogativo, é importante indagar o conteúdo da missiva e seu contexto, quais pessoas e espaços foram descritos, quais roupas eram utilizadas, e o que pode ter sido omitido ou mesmo esquecido.

Durante sua análise, e em especial no olhar dado à moda, Samuel Albuquerque realiza o cruzamento de diferentes correspondências com produções acadêmicas que 
abordam o contexto narrado pela memorialista. Dessa forma, Albuquerque constata que a Rua do Ouvidor era frequentada por Aurélia Dias Rolemberg e sua família, bem como registra o costume feminino de frequentar estabelecimentos de modistas e mandar confeccionar os vestidos visualizados nas ilustrações de moda francesa, presentes nos jornais femininos publicados no Brasil Oitocentista (ALBUQUERQUE, 2015, p. 45).

Diante da falta de recursos técnicos no Brasil, em meados do século XIX, como o computador, a câmera fotográfica, o gravador ou a filmadora, os registros de memória, as ações humanas e os bens adquiridos por distintos indivíduos eram arquivados em missivas, testamentos e outros tipos de papéis públicos e privados.

Enquanto as epístolas adquiriam um caráter privado e eram compostas por desejos, emoções, sentimentos e ações humanas, os testamentos e inventários eram tratados no âmbito público e institucional, uma vez que atribuíam funções e delegava bens de um indivíduo para outro, por meio de heranças, de pagamentos e/ou de outras modalidades. No intento em analisar indumentárias por meio do uso de inventários, Camila Borges da Silva levanta algumas especificidades, análises, procedimentos e questões pertinentes para tratar e construir sua fonte de pesquisa.

Em seu levantamento, a autora destaca que o inventário é um detalhamento dos elementos materiais da vida do falecido no momento em que o documento foi produzido (SILVA, 2018). Isto significa que os bens inventariados não pertenceram ao indivíduo durante toda a sua vida, mas que foram adquiridos ao longo de sua existência.

Levando em consideração que este documento não era uma produção obrigatória naquela época e contexto, e que demandava um custo para sua elaboração, ela circunscreve diferentes classes sociais. Portanto, devemos evitar generalizações ao utilizá-lo, uma vez que os bens pertencentes ao indivíduo poderiam ser omitidos e os valores atribuídos aos produtos inventariados poderiam sofrer alterações, conforme a avaliação feita pelo notário, o que levanta certos cuidados no processo de interpretação e transformação do documento em fonte (SILVA, 2018).

Atenta a estes cuidados, Camila Borges da Silva realiza o cruzamento de três inventários com códigos civis, leis brasileiras, a Ordem Filipina, dicionários de época e obras que tratam do período pesquisado. Desse modo, ela pôde investigar a importância da moda enquanto sistema central no debate sobre a individualidade do gosto e a grande amplitude da coincidência desses mesmos gostos, em um determinado tempo e espaço (SILVA, 2018, p. 152).

Neste sentido, a pesquisadora tem consciência da dificuldade de pesquisar as indumentárias no âmbito da cultura material, uma vez que seu processo de conservação não é simples e nem faz parte da cultura popular a preservação de determinados trajes. Tal dificuldade nos mobiliza a pensar sobre os cuidados e os procedimentos metodológicos ao lidar com este tipo de documento na pesquisa histórica.

Ao considerar a cultura material como todo "segmento do meio físico que é socialmente apropriado pelo homem” (MENESES, 1983, 112) Ulpiano Toledo Bezerra de Meneses situa este documento como suporte material, transformado pelo homem para determinada finalidade da vida social.

Este posicionamento mobiliza Marcelo Rede na busca por minimizar o caráter subalterno que as fontes materiais receberam pelos historiadores em detrimento das fontes impressas (REDE, 2012). Levar em conta a materialidade do objeto, enquanto produto 
e vetor das relações humanas, permite compreender seu processo de produção, o uso dos elementos que constituem a materialidade e fazer distinção das sociedades que a produziram, em determinado tempo e espaço.

No que tange a moda como objeto de pesquisa, Maria Cristina Volpi denota a importância em observar os distintos produtos utilizados na composição de uma indumentária para compreender a estrutura social construtora desta materialidade (VOLPI, 2018, p. 31). O breve percurso do progresso técnico têxtil feito pela pesquisadora é um caminho metodológico por meio do qual é possível situar determinadas "formas vestimentares", códigos de conduta social e relações sociais e culturais estabelecidas entre os distintos indivíduos e grupos (VOLPI, 2018).

Assim como foi feito em outras pesquisas, Maria Cristina Volpi realiza o cruzamento de diferentes documentos, vinculados à cultura material, enquanto fonte de pesquisa, com registros imagéticos, impressos, institucionais, orais, bem como dicionários de época e bibliografias que abordam a moda e o contexto brasileiro na primeira metade do século $X X$.

Dentre as fontes de pesquisa mobilizadas pela pesquisadora, podemos tomar como exemplo alguns registros institucionais para pensar a criação de "formas vestimentares", utilizadas pelos membros do Ministério das Relações Exteriores. Estes documentos oficiais podem servir de fonte para a produção do conhecimento, conforme as questões, abordagens e métodos utilizados para analisar a moda como objeto de pesquisa.

A análise do Decreto de $n^{\circ} 20.041$, de 07 de Maio de 1932, que aprova e manda executar o plano e regulamento para uniformes dos membros dos Corpos Diplomático e Consular, do Decreto de $n^{\circ} 21.498$ de 23 de julho de 1946 e o regulamento dos uniformes dos funcionários do serviço exterior, contribuem para pensarmos os símbolos atribuídos ao uso dos trajes, assim como a hierarquia existente entre os membros do corpo diplomático. Identificar a atuação destes indivíduos, em determinados espaços e suas relações de sociabilidade com outros membros oficiais, levanta indagações a respeito do uso do poder simbólico no acesso e na obtenção de determinados benefícios. Do mesmo modo, permite investigar sobre relação entre identidade individual e coletiva, enquanto indivíduo membro de uma instituição nacional com funções internacionais.

Tratar de documentos oficiais requer pensar quem os produziu e quais foram suas intencionalidades, o assunto abordado, em qual condição ele foi elaborado (decreto, lei, regulamento, parágrafo, inciso, etc.) e seu contexto de produção. Ou ainda, qual o trâmite (votação na câmara de deputados, senadores, etc.) e trajeto percorrido pelo documento oficial até ser publicado, e quais pessoas foram, são e/ou serão atingidas por ele.

Deste modo, é certo que as formas de circulação, difusão e recepção do documento oficial só serão compreendidas de maneira sistemática com a utilização de outras fontes. Os impressos periódicos, os programas de televisão e os documentos digitais são exemplos de fontes que, ao serem cruzadas, podem indicar os comentários e a sua repercussão. Neste sentido, podemos perceber que a mobilização de outros documentos para a produção do conhecimento contribui na resolução das interrogações colocadas pelo pesquisador.

Outra maneira de analisar a cultura material de indumentárias e o universo da moda pode ser realizada na utilização do cinema enquanto fonte de pesquisa. Podemos tomar como exemplo o filme O Diabo Veste Prada (2006), traduzido do inglês The Devil Wears Prada e baseado no livro de mesmo nome, escrito em 2003. 
O simbolismo que o filme traz sobre o universo da moda, as indumentárias trajadas, os discursos utilizados pelas personagens, suas formas de se vestir e agir em cena são alguns dos aspectos que precisam ser problematizados ao mobilizar o documento cinematográfico para analisar a moda enquanto objeto de pesquisa.

A partir desta perspectiva, Marcos Napolitano problematiza o contexto e o local na qual a produção cinematográfica é produzida e na qual os personagens estão situados. Também são levantados os enquadramentos da imagem e dos personagens no decorrer das cenas, os jogos de luz e sombra utilizados, as músicas e sonoridades mobilizadas, os figurinos escolhidos e os signos subjetivos que são emitidos aos telespectadores (NAPOLITANO, 2008).

Seguindo um procedimento metodológico parecido, Alexandre Busko Valim problematiza os indivíduos e grupos que contribuíram para a elaboração da produção cinematográfica. Nesta problematização, é importante considerar os interesses sociais, políticos e econômicos, o público-alvo, o processo de produção, os meios de circulação, de divulgação e de recepção, e as formas de repercussão no âmbito nacional e internacional (VALIM, 2012).

Refletir sobre estes apontamentos requer o cruzamento de outras fontes de pesquisa. No caso da análise do filme O Diabo Veste Prada, a utilização de fontes impressas ligadas ao cinema permite conferir o posicionamento dos críticos de cinema e demais telespectadores a respeito da produção cinematográfica. Averiguar a cultura material das indumentárias produzidas no mesmo período em que o filme foi produzido permite atestar qual era a moda vigente naquele momento. Analisar as músicas utilizadas na produção cinematográfica permite compreender os signos e códigos atribuídos à narrativa dos personagens.

No caso da música, para além dos signos e códigos produzidos pela canção e melodia na produção cinematográfica, outros elementos podem ser analisados, na medida em que este documento também pode ser utilizado como fonte de pesquisa. Marcos Napolitano denota os cuidados que devem ser tomados ao evitar as fragmentações analíticas, ou seja, as separações feitas entre letra e música, contexto e obra, autor e sociedade, estética e ideologia. Para isso, o pesquisador compreende ser importante considerar as manifestações e os estilos musicais dentro de sua época, a cena musical na qual a obra está inserida, os problemas com as hierarquias de valores herdados, a questão do gosto musical individual e coletiva, a articulação entre texto e contexto, os procedimentos poéticos e as figuras de linguagem adotadas na canção (NAPOLITANO, 2005).

Os cuidados com as questões técnicas permite pensarmos, problematizarmos e analisarmos o processo de criação da música, a harmonia, a melodia, o ritmo, a interpretação, o arranjo, a altura, o pulso, o timbre, o vocal e os instrumentos utilizados. $\mathrm{O}$ autor indaga sobre as implicações comerciais, estéticas e ideológicas na qual a produção musical é produzida e inserida, levantando aspectos ligados à gravação, aos veículos de difusão e legitimação da fama, e ao peso simbólico sobre conceitos de passado, herança cultural, tradição, genialidade e obra-prima (NAPOLITANO, 2005). Diante dos distintos recursos tecnológicos que permitem produzir documentos musicais, devemos considerar tais dispositivos como produtores, mas também como armazenadores sonoros. Problematizar o conteúdo digital seja ele musical, imagético e/ou textual permite considerar estes documentos como fonte de pesquisa. 
As questões levantadas acerca da atitude dos pesquisadores frente ao uso de fontes digitais são analisas por Anaclet Pons a fim de refletir sobre os desafios existentes no século XXI (PONS, 2011). Para tratar dos problemas que o documento digital possui, enquanto fonte de pesquisa, o pesquisador compreende ser necessário considerar que o digital faz parte do cotidiano e do contexto atual da experiência humana. $\mathrm{O}$ uso de e-mails, a buscas por informações em sites de busca, o pagamento de contas, os recursos de telecomunicação estão nas palmas das mãos, transformando as relações humanas. Considerar a maneira que os indivíduos e as sociedades lidam com os recursos digitais permite compreender os hábitos de leitura e interpretação, assim como as relações sociais e culturais mediadas pelas diversas tecnologias (PONS, 2011).

Deste modo, Anaclet Pons leva em consideração a questão do acesso por parte dos usuários a determinados conteúdos, o processo de digitalização e arquivamento de distintas fontes, as empresas digitais que monopolizam certos recursos, e a construção de efeitos de verdade e de mentira por parte de indivíduos, que são propagados, replicados e que mobilizam novas ações e reações por parte dos demais usuários que recebem estes conteúdos (PONS, 2011). As preocupações levantadas por Anaclet Pons também são questionadas por Célia Cristina da Silva Tavares ao problematizar o acesso, o arquivamento, a disponibilização, o capital simbólico e econômico e as tensões que envolvem os detentores dos conteúdos e os usuários, bem como a falta de domínio sobre o que é salvo ou apagado e a relação da verdade produzida na era digital (TAVARES, 2012).

Cientes de que a produção histórica deste século não pretende narrar a verdade, mas apreender as distintas dimensões de realidades vividas no tempo e no espaço, a análise dos documentos digitais deve conduzir o pesquisador na compreensão das modalidades de verdade que são construídas com distintas finalidades.

Desta maneira, sejam no sentido de compor, sobrepor ou contrapor narrativas históricas que foram legitimadas por outras fontes, os efeitos de verdade produzidos pelas fontes digitais, no século XXI, sinalizam novas abordagens, métodos e problemas que não serão contemplados nesta proposta, por razões metodológicas, mas que se colocam como chave de pensamento nos cuidados necessários para a utilização das distintas fontes e objetos de pesquisa pelo historiador e por demais pesquisadores.

\section{CONCLUSÃO}

Como destacamos nesta proposta, o estudo das fontes de pesquisa a partir das questões colocadas, das reflexões feitas, dos fundamentos teóricos utilizados e das propostas metodológicas adotadas nos diversos documentos mencionados ao longo deste artigo demanda um esforço hercúleo para o pesquisador que pretende utilizá-los em seu ofício. Ainda que possa parecer uma tarefa árdua, as interrogações e exclamações teóricas e metodológicas feitas às fontes de pesquisa permitem compreender e situar as diversas possibilidades de pesquisa no tempo e no espaço histórico.

Tomando a moda como objeto de pesquisa, levantamos alguns trabalhos que mobilizaram diversas fontes a fim de apresentar, problematizar e analisar alguns dos procedimentos metodológicos utilizados e que podem sinalizar e sugerir múltiplos caminhos de análise para estudar a História e a Moda.

Por fim, nesta proposta foi possível compreender que a guinada histórica, iniciada em fins do século $X X$, deu margem para pensarmos algumas abordagens, métodos e 
problemas que se colocam em nosso século para cruzarmos as distintas fontes históricas na análise da moda enquanto objeto de pesquisa.

Agora que conhecemos as ferramentas e seus usos, podemos contribuir de modo mais efetivo para a construção do conhecimento histórico. Mãos à obra!

\section{FONTES}

GOUBAULD, Adolphe Camille. Le Moniteur de la mode. Paris: Imprimerie de E. Martinet, 1843-1913.

MINISTÉRIO DAS RELAÇÕES EXTERIORES. Decreto n. 20.041, de 7 de Maio de 1932: Aprova e manda executar o plano e regulamento para os uniformes dos membros dos Corpos Diplomático e Consular. Rio de Janeiro: Imprensa Nacional, 1933.

Decreto $n^{0} 21.498$ de 23 de julho

de 1946 e regulamento: Uniformes dos funcionários do serviço exterior. Rio de Janeiro: Imprensa Nacional, 1946.

NORONHA, Joanna Paula Manso de; VELASCO, Violante Atabalipa Ximenes de Bivar e; NEVES, Gervasia Nunésia Pires dos Santos. O Jornal das Senhoras. Rio de Janeiro: Tipografia do Jornal das Senhoras, 1852-1855.

\section{REFERÊNCIAS}

ALBUQUERQUE, Samuel. Nas memórias de Aurélia: cotidiano feminino no Rio de Janeiro do século XIX. São Cristóvão: Editora UFS, 2015.

BARBOSA, Everton Vieira. Páginas de sociabilidade feminina: sensibilidade musical no Rio de Janeiro Oitocentista. São Paulo: Alameda, 2018.

BARTHES, Roland. Sistema da moda. Tradução Lineide do Lago Salvador; revisão e supervisão Isaac Nicolau Salum. São Paulo: Ed. Nacional; Ed. Da Universidade de São Paulo, 1979.

BRAUDEL, Fernand. História e ciências Sociais: a longa duração. Revista de História, $n^{\circ} 65$, vol. XXX, ano XVI, abril-junho, 1965, pp. 261-294. Disponível em < http://www. revistas.usp.br/revhistoria/article/view/123422/ >. Acesso em 14 jul. 2019.

CARDOSO, Ciro Flamarion; MAUAD, Ana Maria. História e Imagem: os exemplos da fotografia e do cinema. In: CARDOSO, Ciro Flamarion; VAINFAS, Ronaldo (Orgs.). Domínios da História: Ensaios de Teoria e Metodologia. Rio de Janeiro, Campus, 1997, pp. 564-584.

CHARTIER, Roger. A história cultural: entre práticas e representações. Tradução de Maria Manuela Galhardo. $2^{\mathrm{a}}$ ed. Rio de Janeiro: Difel, 2002.

CRANE, Diana. A moda e seu papel social: classe, gênero e identidade das roupas. Trad. Cristiana Coimbra. São Paulo: Editora Senac, 2006.

HAHN, H. Hazel. Scenes of parisian modernity: culture and consumption in the nineteenth century. New York: Palgrave Macmillan, 2009.

LARA, Sílvia Hunold. "Os documentos textuais e as fontes do conhecimento histórico". Anos 90, Porto Alegre, v. 15, n. 28, dez. 2008, pp. 17-39. Disponível em <https://seer. ufrgs.br/anos90/article/view/7953/4740>. Acesso em 19 jun. 2019. 
LEPETIT, Bernard. Por uma nova história urbana. Seleção de textos, revisão crítica e apresentação Heliana Angotti Salgueiro. Tradução Cely Árena. São Paulo: Editora da Universidade de São Paulo, 2001.

LUCA, Tania Regina de. História dos, nos e por meio dos periódicos. In: PINSK, Carla Bassanezi (Org.). Fontes históricas. $2^{\mathrm{a}}$ ed. $1^{\mathrm{a}}$ reimp. São Paulo: Contexto, 2008, pp. 111-154.

MENESES, Ulpiano Toledo Bezerra de. A cultura material no estudo das sociedades antigas. Revista de História, n. 115, 1983, p. 103- 117. Disponível em < http://www.revistas. usp.br/revhistoria/article/view/61796/64659 >. Acesso em 14 jul. 2019.

. História e imagem: iconografia/iconologia e além. In: CARDOSO, Ciro Flamarion; VAINFAS, Ronaldo (Orgs.). Novos domínios da História. Rio de Janeiro: Ensevier, 2012, pp. 243-262.

NAPOLITANO, Marcos. A História depois do papel. In: PINSK, Carla Bassanezi (Org.). Fontes históricas. $2^{\mathrm{a}}$ ed. $1^{\mathrm{a}}$ reimp. São Paulo: Contexto, 2008, pp. 235-290.

História \& Música: 3ª ed. Belo Horizonte, MG: Autêntica, 2005.

PEIXOTO, Maria do Rosário da Cunha. Saberes e sabores ou conversas sobre história e literatura. Revista História \& Perspectiva, Uberlândia, UFU, v.24, n. 45, 2001, pp. 15-33. Disponível em: <http://www.seer.ufu.br/index.php/historia perspectivas/article/ view/19401> Acesso em 14 jul. 2019.

PEIXOTO, Maria do Rosário da Cunha; CRUZ, Heloísa de Faria. Na oficina do historiador: conversas sobre história e imprensa. Projeto História. São Paulo, $n^{\circ} 35$, p. 253-270, dez. 2007. Disponível em <https://revistas.pucsp.br/index.php/revph/ article/ view/2221/1322>. Acesso em 14 jul. 2019.

PONS, Anaclet. "Guardar como". La historia y las fuentes digitales. Historia Crítica. No 43, Bogotá, enero-abril, 2011, 260, pp. 38-61. Disponível em <http://www.scielo.org.co/ pdf/rhc/n43/n43a04.pdf>. Acesso em 14 jul. 2019.

PORTELLI, Alessandro. Ensaios de história oral. Trad. Fernando Luiz Cássio e Ricardo Santhiago. São Paulo: Letra e Voz, 2010.

REDE, Marcelo. História e cultura material. In: CARDOSO, Ciro Flamarion; VAINFAS, Ronaldo (Orgs.). Novos domínios da História. Rio de Janeiro: Ensevier, 2012, 133-150.

SALOMON, Geanneti Tavares. Moda e ironia em Dom Casmurro. São Paulo: Alameda, 2010.

SILVA, Ana Claudia Suriani da. Moda, transferências culturais e história do livro. Dobras, vol. 10, n 22, novembro, 2017, pp. 177-201. Disponível em <https://dobras.emnuvens. com.br/dobras/article/view/642/471>. Acesso em 14 jul. 2019.

SILVA, Camila Borges da. Os inventários no estudo da indumentária. ACERVO, Rio de Janeiro, v. 31, $\mathrm{n}^{\mathrm{a}}$ 02, p. 142-160, maio/ago. 2018. Disponível em <http://revista.arquivonacional.gov.br/index.php/revistaacervo/article/view/911/942>. Acesso em 14 jul. 2019.

SILVA, Helenice Rodrigues da. A renovação historiográfica francesa após a "Guinada Crítica". In: MALERBA, Jurandir; ROJAS, Carlos Aguirre (Orgs.). Historiografia contemporânea em perspectiva crítica. Bauru, SP: Edusc, 2007 (Coleção História), pp. 167-186.

TAVARES, Célia Cristina da Silva. História e Informática. In: CARDOSO, Ciro Flamarion; VAINFAS, Ronaldo (Orgs.). Novos domínios da História. Rio de Janeiro: Ensevier, 2012, pp. 301-317. 
THOMSON, Alistair. Recompondo a memória: questões sobre a relação entre história oral e as memórias. Projeto História (PUCSP), n. 15, pp. 51-71, 1997. Disponível em <http://revistas.pucsp.br/index.php/revph/article/view/11216>. Acesso em 14 jul. 2019.

VALIM, Alexande Busko. História e cinema. In: CARDOSO, Ciro Flamarion; VAINFAS, Ronaldo (Orgs.). Novos domínios da História. Rio de Janeiro: Ensevier, 2012, pp. 283300.

VENANCIO, Giselle Martins; VIANNA, Larissa; SECRETO, Maria Verónica. Sujeitos na História: perspectivas e abordagens. Niterói/RJ: Eduff, 2017.

VOLPI, Maria Cristina. Estilo urbano: modos de vestir na primeira metade do século XX no Rio de Janeiro. São Paulo: Estação das Letras e Cores, 2018.

Recebido em: 16/08/2019

Aceito em: 13/09/2019

DOI: http://dx.doi.org/10.5965/25944630332019027 